“(C) 2015 IEEE. Personal use of this material is permitted. Permission from IEEE must be obtained for all other uses, in any current or future media, including reprinting/republishing this material for advertising or promotional purposes, creating new collective works, for resale or redistribution to servers or lists, or reuse of any copyrighted component of this work in other works." 


\title{
A Low-Cost Permanent Magnet Synchorous Motor with SMC and Ferrite PM
}

\author{
Chengcheng Liu ${ }^{1}$, Jianguo Zhu ${ }^{2}$, Youhua Wang ${ }^{1}$, Gang Lei ${ }^{2}$, Youguang Guo ${ }^{2}$, Xiaojing Liu ${ }^{1}$ \\ ${ }^{1}$ Province-Ministry Joint Key Laboratory of EFEAR, Hebei University of Technology, Tianjin, China \\ ${ }^{2}$ School of Electrical, Mechanical and Mechatronic System, University of Technology, Sydney, Sydney, Australia \\ E-mail: Chengcheng.Liu@uts.edu.au
}

\begin{abstract}
This paper proposes a low-cost permanent magnet synchronous motor (PMSM) with soft magnetic composite (SMC) and ferrite permanent magnet (PM) for home applications. The main novelty of this proposed motor is that it combines two relatively cheap magnetic materials in an axial flux switching permanent magnet motor (AFSPMM). By using the ferrite $P M$ and SMC material, the material cost and manufacture cost of AFSPMM can be reduced greatly. A 675 W 3600 rpm AFSPMM is designed and analyzed in this paper. The commercial finite element method (FEM) package ANSOFT is used to analyze the motor performance and the d-axis current is set to zero to achieve the optimum torque characteristic.
\end{abstract}

Index Terms-Low-cost permanent synchronous magnet motor, soft magnetic composite, ferrite permanent magnet, axial flux switching permanent magnet motor.

\section{INTRODUCTION}

Rare earth permanent magnet (PM) materials have been applied in the electric motors. The permanent magnet synchronous motor (PMSM) shows higher efficiency and higher power density when compared with induction motor and switched reluctance motor. However, the price of the rare earth PM is very high, which makes the PMSM comparatively expensive. For the low-cost home applications such as electrical fan, washing machine and refrigerator, the PMSM with rare-earth PM is not a good candidate. By comparing the magnetic performance and cost of all commercial PM materials, it can be found that the cost of ferrite PM is the lowest, and it can be used to produce the PM flux in a PMSM. However, the energy product of the ferrite PM is low. Therefore, the flux concentrating structure should be applied in the motors with ferrite PM, and the spoke structure is attractive. During last decades, various researches have been done on improving the performance of the PMSM with ferrite magnets. In 2013, Kim et al. proposed a modified spoke type ferrite magnet motor. Compared with the traditional spoke type ferrite magnet motor, the main performances of this motor are improved except the efficiency [1]. In 2013, Petrov et al. analyzed an outer rotor PMSM with ferrite magnets, showing that the PMSM with ferrite magnet has lower performance than the PMSM with NdFeB, but has better performance than induction machines [2]. However, it doesn't use any special topology to improve the performance of a PMSM with ferrite $\mathrm{PM}$. The ferrite magnets produce PM torque in the PMSM. They can also be used to produce a PM torque in the synchronous reluctance motor [3]. Among various PMSM topologies, the flux switching permanent magnet motor (FSPMM) has special high flux concentrating structure, it is a good candidate for designing with ferrite PM.

Soft magnetic composite (SMC) is a relatively new soft magnetic material which can be used to manufacture the electromagnetic device [4]. Because of its magnetic isotropy characteristic and powder metallurgy technology, it can be used to prototype various complex three dimensional (3D) electromagnetic devices. Among them, the claw pole motor and transverse flux motor are excellent examples. Besides the special physical characteristics, manufacturing a motor with SMC core can reduce the manufacture cost greatly [5]-[8], considering that there is even no material waste and the material cost of SMC is quite close to that of silicon steels. The SMC is a good candidate for the low cost commercial PMSM applications. On the other hand, the disadvantages of the SMC are that its permeability is quite low and its core loss is relatively high in low frequencies.

In the home applications, the most important factor is not just the motor performance, but the ratio of the performance to the cost. In this paper, a compressor motor for refrigerator is designed. The requirements for the target motor are listed in Table I.

In this paper, an axial flux switching permanent magnet motor (AFSPMM) with SMC core and ferrite PM is proposed. By analyzing its performance and cost, it can be found that this motor can meet the general home application requirement and only AUD \$6.8 of materials are needed. Part II introduces the motor topology, Part III analyzes the electromagnetic parameters of AFSPMM by finite element method (FEM) package ANSOFT, and Part IV presents the performance prediction. Part V concludes the paper.

TABLE I

REQUIREMENTS FOR THE TARGET MOTOR

\begin{tabular}{|c|c|}
\hline Rated speed & $3600 \mathrm{rpm}$ \\
\hline Rated torque & $1.8 \mathrm{Nm}$ \\
\hline Rated torque & $675 \mathrm{~W}$ \\
\hline Rated efficiency & $80 \%$ \\
\hline Maximum speed & $7200 \mathrm{rpm}$ \\
\hline Minimum speed & $1200 \mathrm{rpm}$ \\
\hline Maximum power & $900 \mathrm{~W}$ \\
\hline Supply voltage & $230 \mathrm{~V}$ \\
\hline Outer radius of the motor & $55 \mathrm{~mm}$ \\
\hline Axial length & $60 \mathrm{~mm}$ \\
\hline
\end{tabular}




\section{TOPOLOGY, OPERATIONAL PRINCIPLE AND DiMENSIONS OF THE AFSPM WITH FERRITE MAGNET}

\section{A. Topology introduction}

Fig. 1 shows the 3D view of the AFSMM. It has six U shape stator pole cores, six ferrite PMs and a rotor core with seven rotor poles. The concentrating windings are wounded around the stator cores. The rotor and stator cores are built by SMC. Based on the powder metallurgy technology, the stator and the rotor cores can be compressed in two molds separately, and then arranged as a complete motor as shown in Fig 1. There are no windings or magnets on the rotor.

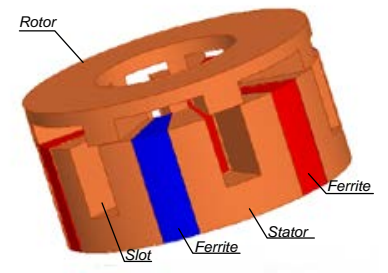

Fig. 1. Topology of the AFSPMM

\section{B. Operational principle of AFSPMM}

The operational principle of AFSPMM is similar to that of flux switching permanent magnet motor (FSPMM). The only difference between them is that the flux direction of AFSPMM is along the axial direction while the flux of FSPMM is along the radial direction.
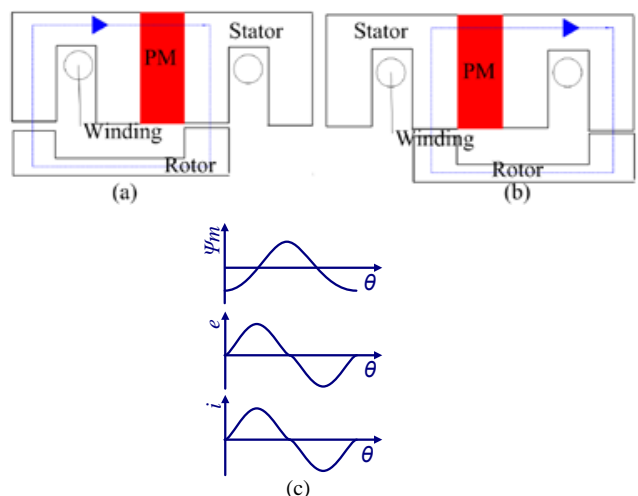

(c)

Fig. 2. Operational principle of FSPMM. (a), (b) "Flux switching" principle, (c) The ideal phase PM flux linkages, back EMF and armature current.

Fig. 2 shows the basic flux switching concept for the FSPMM. When the rotor is aligned with the stator pole on the right side of PM, as shown in Fig. 2(a), it can be found that the flux flows out from the stator pole; it will produce a maximum positive flux linkage. Assuming that the rotor moves along the clockwise direction, the rotor will move to a position under the stator slot. As the magnetic reluctance of the air of slot is very large, the flux linking the winding is almost zero. Then, the rotor continues to move and aligns with the stator pole on the left side of PM, as shown in Fig. 2(b), and a maximum negative flux linkage is produced. As the rotor moves, the ideal phase PM flux linkages, back EMF and armature current are shown in Fig. 2(c).

\section{Initial design of AFSPMM}

The flux linkage and back electromotive force (EMF) of the AFSPMM are sinusoidal. When the reactance is neglected, the current is in phase with the back EMF, and the electromagnetic power can be expressed as

$$
P_{e m}=\frac{m E_{m} I_{m}}{2}
$$

where $P_{e m}$ is the electromagnetic power, $m$ the number of phases, $E_{m}$ the back EMF in magnitude value, and $I_{m}$ the phase current in magnitude value. The flux linkage per coil $\Phi_{p m}$ can be expressed as

$$
\Phi_{p m}=k_{d} k_{f} B_{g \max } \frac{1}{P_{s}} \frac{\pi}{4}\left(D_{s o}{ }^{2}-D_{s i}{ }^{2}\right)
$$

where $k_{d}$ is leakage flux coefficient, $k_{f}$ the air gap flux density distribution coefficient, $B_{\operatorname{gmax}}$ the maximum value of air gap flux density, Ps the number of stator poles, $D_{\text {so }}$ the outer diameter of stator, and $D_{s i}$ the inner diameter of stator.

The phase back EMF can be expressed as

$$
E_{m}=N_{\text {coil }} \omega_{r} P_{r} \Phi_{p m}
$$

where $N_{\text {coil }}$ is the number of coil turns per phase, $\omega_{r}$ the mechanical angular speed, and $P_{r}$ the number of rotor poles. The phase current $I_{m}$ can be expressed as

$$
I_{m}=\frac{\sqrt{2} A_{s} D_{s i}}{2 m N_{\text {coil }}}
$$

where $A_{s}$ is the line current density. Substituting (3) and (4) into (1), the power equation can be expressed as

$$
P_{e m}=\frac{m}{2} N_{c o i l} \omega_{r} P_{r} \Phi_{p m} I_{m}
$$

The output torque can be expressed as

$$
T_{e m}=\frac{P_{e m}}{\omega_{r}}=\frac{m}{2} N_{c o i l} P_{r} \Phi_{p m} I_{m}
$$

Based on the above equations, the initial dimensions of the AFSPMM can be estimated. Table II lists the main dimensions of the AFSPMM.

TABLE II

DIMENSIONS OF THE AFSPMM

\begin{tabular}{|c|c|}
\hline Stator outer radius & $55 \mathrm{~mm}$ \\
\hline Stator inner radius & $30 \mathrm{~mm}$ \\
\hline Stator axial length & $45 \mathrm{~mm}$ \\
\hline Rotor length & $15 \mathrm{~mm}$ \\
\hline Number of the stator poles/ rotor poles & $6 / 7$ \\
\hline Air gap length & $1 \mathrm{~mm}$ \\
\hline Turns of coil per phase & 125 \\
\hline Material of the stator and rotor & SMC \\
\hline Material of the PM & ferrite \\
\hline Arc of PM, stator pole, rotor pole and slot/degree & 15 \\
\hline Stator yoke length & $15 \mathrm{~mm}$ \\
\hline Rotor pole height & $9 \mathrm{~mm}$ \\
\hline
\end{tabular}




\section{EleCtRomagnetic PARAMETERS CALCULATION}

As the structure of the AFSPMM is very complex, the accurate electromagnetic performance analysis should be completed by FEM such as the commercial FEM package ANSOFT. In this paper, the complete 3D FEM model of AFSPMM is built, and the nonlinear characteristic of the SMC is considered. The air gap flux density in the radial direction, flux linkages, back EMF and core loss are all analyzed.

\section{A. Air gap flux density analysis}

Air gap flux density is a very important parameter which can affect the major performance of the motor. Based on (2) and (6), it can be found that the torque is proportional to the air gap flux density. Fig. 3 shows the air gap flux density distribution in the radial direction. Though the residual flux density the ferrite magnet is $0.4 \mathrm{~T}$, by using the special high flux concentrating structure, its peak value can reach $1.0 \mathrm{~T}$.

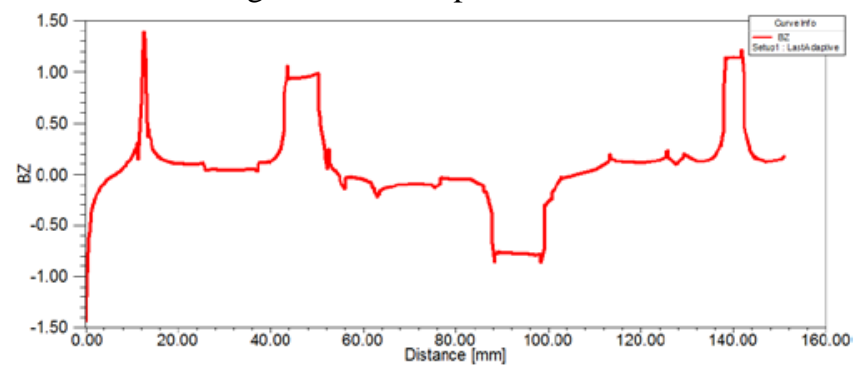

Fig. 3. Air gap flux density of AFSPM

\section{B. Inductance analysis}

The inductance of the motor can be obtained by

$$
L=\frac{\varphi_{I+P M}-\varphi_{P M}}{I}
$$

where $L$ is the inductance, $\varphi_{I+P M}$ the flux linkage of armature produced by the armature current and PM together, $\varphi_{P M}$ the flux linkage that is produced by the PM only, and $I$ the armature current. In the PMSM, the inductance can be classified as d-axis inductance and q-axis inductance, the difference between the d-axis inductance and q-inductance will produce the reluctance torque. However, in the FSPM, there is only a slight difference between these two kinds of inductance.

\section{PM Flux linkage and EMF analysis}

As the rotor rotates, the PM flux linking stator winding varies with the different position. Differentiating the PM fluxes, the back EMF will be obtained. Consequently, the magnitude of the back EMF is decided by the PM flux and rotor speed. Fig. 4 shows the PM flux linkage of the motor, which was calculated by the FEM. Fig. 5 shows the phase back EMF prediction. It can be seen from the figures that the flux linkages per phase have a 120 electrical degree shift from each other. The magnitude value of flux linkage per phase is 0.036 $\mathrm{Wb}$, and the magnitude value of back EMF at the speed of $3600 \mathrm{rpm}$ is $91 \mathrm{~V}$.

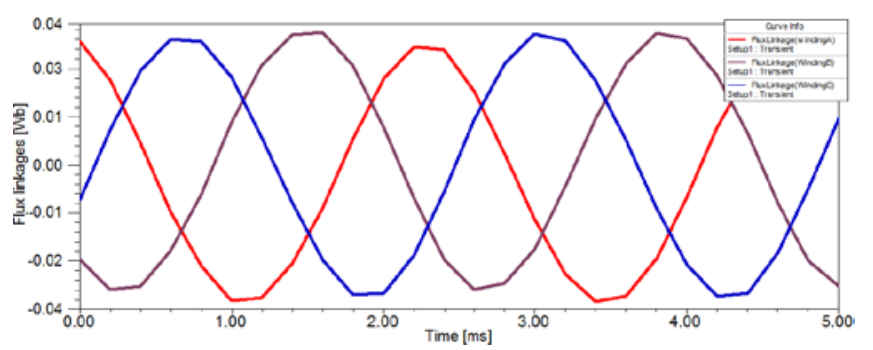

Fig. 4. PM flux linkages of the motor

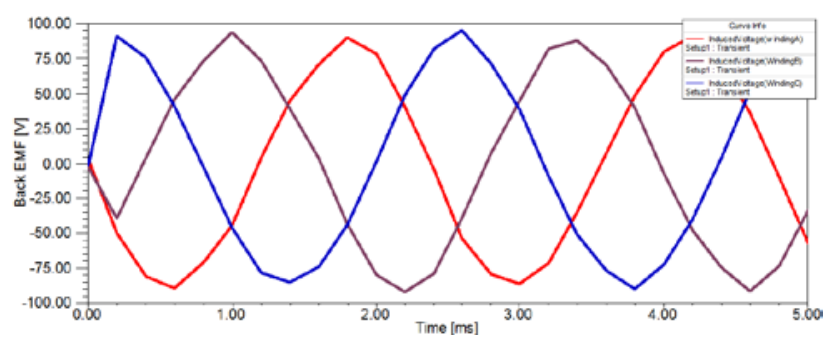

Fig. 5. EMF of the AFSPM with the rotary speed of $3600 \mathrm{rpm}$

\section{PERFORMANCE PREDICTION AND COST ANALYSIS}

\section{A. Torque prediction}

The performance of AFSPMM can be predicted by the simplified equivalent electrical circuit model of AFSPMM. In this paper, the phase current is forced to have same phase as the no load back EMF. It means that the d-axis current is equal to zero. In this control model, only the PM torque is effective. Fig. 6 shows the output torque when the q-axis current is equal to $4 \mathrm{~A}$. The average torque is $1.833 \mathrm{Nm}$ as shown in Fig. 6.

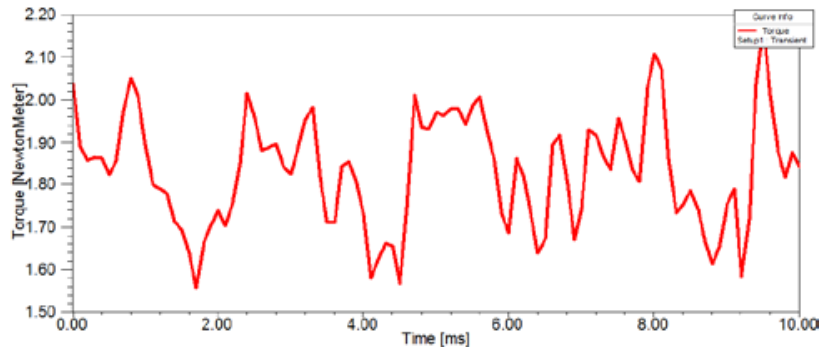

Fig. 6. Electromagnetic torque when the $\mathrm{q}$ axis current is $4 \mathrm{~A}$

\section{B. Efficiency analysis}

In a PMSM, the losses are composite of core loss, copper loss and mechanical loss. In the PMSM with SMC core, the core loss is the major part among these losses. The mechanical loss is generally considered as $1 \%$ or $1.5 \%$ of the total output power. In the ANSOFT, the core loss calculation depends on the material's multi-frequency core loss characteristics. Fig. 7 shows its core loss. And the copper loss can be estimated by

$$
P_{\text {copper }}=m R I_{a}^{2}
$$

where $R$ is phase winding resistance. In this motor, the phase resistance of the motor is $0.38 \mathrm{ohm}$, and the copper loss is 18.24 W. The efficiency can be calculated by 


$$
\eta=\frac{P_{\text {out }}}{P_{\text {out }}+P_{\text {mech }}+P_{\text {core }}+P_{\text {copper }}}
$$

where $P_{\text {out }}$ is the output power that can be calculated by multiplying the output torque with the rotor speed, $P_{\text {mech }}$ is the mechanical loss, $P_{\text {core }}$ is the core loss, and $P_{\text {copper }}$ is the copper loss. It can be calculated that the efficiency is $80.8 \%$ at the rated state.

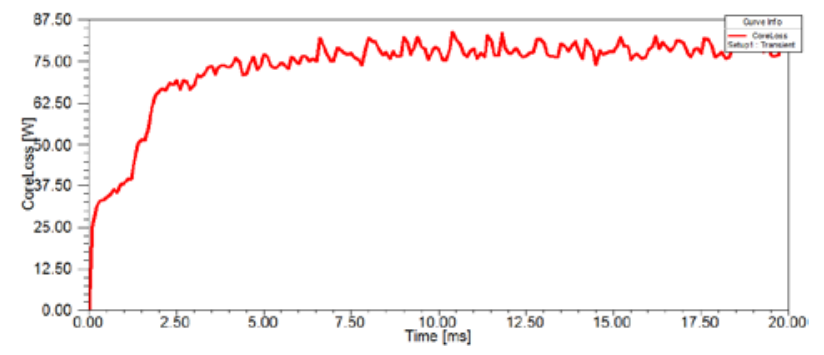

Fig. 7. Core loss prediction at the speed of $3600 \mathrm{rpm}$

The parameters of the AFSPMM are listed in Table III which can be used to analyze its performance.

TABLE III

\begin{tabular}{|c|c|} 
BASIC PARAMETERS OF THE AFSPMM \\
\hline Inductance & $9 \mathrm{mH}$ \\
\hline Resistance(phase) & $0.38 \mathrm{ohm}$ \\
\hline PM flux linkage & $0.038 \mathrm{~Wb}$ \\
\hline EMF constant (phase) & $25.46 \mathrm{~V} / \mathrm{krpm}$ \\
\hline Torque constant & $0.458 \mathrm{Nm} / \mathrm{A}$ \\
\hline
\end{tabular}

$$
\begin{aligned}
& T_{e m}=T_{c} I_{a} \\
& E_{m}=E_{c} \omega_{r}
\end{aligned}
$$

where $T_{e m}$ is the electromagnetic torque, $T_{c}$ the torque constant, $I_{a}$ the armature current in peak value, $E_{m}$ the back EMF, $E_{c}$ the EMF constant, and $\omega_{r}$ the mechanical angular speed.

\section{Cost evaluation}

In the AFSPMM with SMC core, the material cost takes the major part. It is because that the manufacture process of the SMC core is simple and no special measures to wound the coils in this motor. Consequently, only the material cost will be counted in this paper. The total material cost is AUD \$6.8 which based on the basic material price shown in Table IV.

TABLE IV

\begin{tabular}{|c|c|}
\hline \multicolumn{2}{|c|}{ BASIC MATERIAL PRICE OF THE AFSPMM } \\
\hline Items & Price per kilogram (AUD/kg) \\
\hline Coil & 6 \\
\hline Ferrite magnet & 2 \\
\hline SMC & 1 \\
\hline
\end{tabular}

\section{CONCLUSION}

A novel AFSPMM with SMC core and ferrite PM is proposed in this paper. As the ferrite PM and SMC materials are used to manufacture the AFSPMM, its material cost will be reduced greatly. The high flux concentrating structure of
AFSPMM makes the ferrite PM produce relatively high PM flux linkage in the stator winding, which improves the torque capability of a PMSM with ferrite PM. A $675 \mathrm{~W}$ AFSPMM is designed for the refrigerator compressor. By using the commercial FEM package ANSOFT to analyze the electromagnetic performance and calculating the motor material cost, it can be found that the AFFSPMM can meet the design requirements with only AUD \$6.8 materials needed.

\section{REFERENCES}

[1] S. I. Kim, J. Cho, S. Park, T. Park, and S. Lim, "Characteristics comparison of a conventional and modified spoke-type ferrite magnet motor for traction drives of low-speed electric vehicles," IEEE Transactions on Industry Applications, vol. 49, pp. 2516-2523, 2013.

[2] I. Petrov and J. Pyrhonen, "Performance of low-cost permanent magnet material in PM synchronous machines," IEEE Transactions on Industrial Electronics, vol. 60, pp. 2131-2138, 2013.

[3] S. Ooi, S. Morimoto, M. Sanada, and Y. Inoue, "Performance evaluation of a high-power-density PMASynRM with ferrite magnets," IEEE Transactions on Industry Applications, vol. 49, pp. 1308-1315, 2013.

[4] Y. P. Dou, Y. G. Guo, and J. G. Zhu, "Investigation of motor topologies for SMC application,” International Conference on Electrical Machines and Systems, 2007, pp. 695-698.

[5] J. G. Zhu, Y. G. Guo, Z. W. Lin, Y. J. Li, and Y. K. Huang, "Development of PM transverse flux motors with soft magnetic composite cores,” IEEE Transactions on Magnetics, vol. 47, pp. 43764383, 2011.

[6] Y. G. Guo, J. G. Zhu, and D. G. Dorrell, "Design and analysis of a claw pole permanent magnet motor with molded soft magnetic composite core,” IEEE Transactions on Magnetics, vol. 45, pp. 4582-4585, 2009.

[7] Y. K. Huang, J. G. Zhu, Y. G. Guo, Z. W. Lin, and Q. S. Hu, "Design and analysis of a high-speed claw pole motor with soft magnetic composite core,” IEEE Transactions on Magnetics, vol. 43, pp. 24922494, 2007.

[8] Y. G. Guo, J. G. Zhu, Z. W. Lin, and J. J. Zhong, "Measurement and modeling of core losses of soft magnetic composites under 3-D magnetic excitations in rotating motors,” IEEE Transactions on Magnetics, vol. 41, pp. 3925-3927, 2005. 